\title{
CONTRIBUIÇõES E LIMITES DA ABORDAGEM ANALÍTICA NA FILOSOFIA DA PSICOLOGIA DE LUDWIG WITTGENSTEIN
}

\author{
Pedro Dulci ${ }^{1}$ \\ Universidade Federal de Goiás (UFG) \\ (D) https://orcid.org/0000-0002-8794-9643
}

RESUMO:

Toda uma nuvem de Filosofia está condensada numa pequenina gota de gramática (Ludwig Wittgenstein)

O presente artigo tem como objetivo apresentar as contribuições de Ludwig Wittgenstein à fundamentação do saber e prática psicológica. Isso será feito em dois movimentos fundamentais: em primeiro lugar, reconstruiremos os interlocutores de Wittgenstein (psicologia empírica, fenomenologia e psicanálise freudiana) e as questões que estavam pressupostas em cada um deles (cartesianismo e uso impreciso da linguagem). Em segundo lugar, argumentaremos sobre o método analítico que Wittgenstein escolheu para lidar com essas questões. Isto significa, pelo menos, duas coisas: (1) Wittgenstein assume que a linguagem descritiva (dos fatos no mundo) é o padrão para a interlocução humana, mas que também a linguagem expressiva (das ocorrências subjetivas) tem seu lugar de importância, ainda que com ressalvas; (2) essa distinção de gramáticas fundamentará o seu método de lidar com as questões psicológicas: através da interpretação e descrição do comportamento, entendido como manifestação externa das vivências internas, a terceira pessoa terá um acesso privilegiado às ocorrências da consciência da primeira pessoa. Concluiremos o trabalho com considerações críticas sobre os benefícios e as deficiências da abordagem wittgensteiniana.

PALAVRAS-CHAVE: Consciência; Linguagem; Psicologia; Expressão; Descrição.

\section{CONTRIBUTIONS AND LIMITS IN THE ANALYTICAL APPROACH OF LUDWIG WITTGENSTEIN'S PHILOSOPHY OF PSYCHOLOGY}

\begin{abstract}
:
This article aims to present the contributions of Ludwig Wittgenstein to the foundation of psychological knowledge and practice. This will be done in two fundamental movements: first, we will reconstruct Wittgenstein's interlocutors (empirical psychology, phenomenology and Freudian psychoanalysis) and the questions that were presupposed in each of them (Cartesianism and imprecise use of language). Second, we will argue about the analytic method that Wittgenstein chose to deal with these questions. This means at least two things: (1) Wittgenstein assumes that the descriptive language (of facts in the world) is the standard for human interlocution, but that expressive language (of subjective occurrences) also has its place of importance, still that with reservations; (2) this distinction of grammars will justify his method of dealing with psychological issues: through the interpretation and description of behavior, understood as an external manifestation of inner experiences, the third person will have privileged access to the occurrences of first-person consciousness. We will conclude with critical considerations on the benefits and shortcomings of the Wittgensteinian approach.
\end{abstract}

KEYWORDS: Consciousness; Language; Expression; Description; Psychology.

1 Doutorando em Filosofia na Universidade Federal de Goiás (UFG), Goiás - Brasil. E-mail: pedrolucas.dulci@gmail.com

DULCI, Pedro. Contribuições e limites da abordagem analítica na filosofia da psicologia de Ludwig Wittgenstein. Griot : Revista de Filosofia, Amargosa/Bahia, v.17, n.1, p.240-255, junho/2018. 


\section{Introdução}

Tornou-se recorrente nos manuais introdutórios a respeito do pensamento de Ludwig Wittgenstein a afirmação de que sua obra é dividida em dois períodos bem distintos. Enquanto o "primeiro Wittgenstein" corresponde ao Tractatus LogicoPhilosophicus, o "segundo Wittgenstein" encontra-se em suas demais obras, mas, principalmente, nas Investigações Filosóficas. Além disso, junto a essa diferenciação muito rígida, existe também uma segunda atribuição à obra do vienense que é igualmente recorrente nas introduções ao seu pensamento. Trata-se da divisão entre filosofia analítica e filosofia continental - localizando Wittgenstein claramente como um distinto representante da primeira.

Visivelmente tais descrições são caricatas e desconsideram, não apenas as três décadas que separam as duas publicações de Wittgenstein - chamado período intermediário -, como também são insensíveis às próprias sutilezas do pensamento do autor que mantém muitas convicções intactas ao longo de toda sua vida. Conforme comenta Mário Micheletti, "não obstante as mudanças pelas quais passou o pensamento de Wittgenstein, há uma evidente continuidade em seu modo de conceber a filosofia" (2007, p. 17). Já no Prefácio ao Tractatus, por exemplo, Wittgenstein exprime uma das convicções que carregará consigo em toda sua atividade filosófica, e que também será importante para o presente trabalho. A saber, de que a formulação dos problemas filosóficos "se funda na má compreensão da lógica de nossa linguagem" (2001, p. 3). Ainda que essa "má compreensão" varie um pouco na sua forma em cada uma dessas duas obras, o que permanece como um mínimo múltiplo comum no pensamento de Wittgenstein é essa convicção que alimenta sua postura filosófica: de que somente por uma análise da linguagem é possível lidar filosoficamente com o pensamento. Nas suas próprias palavras nas Investigações Filosóficas: "levanta o nevoeiro estudarmos os fenômenos da linguagem em formas primitivas do seu emprego, nas quais se pode ter uma visão panorâmica da finalidade do funcionamento das palavras" $(2001$, p. $175, \S 5)$.

Para alguns leitores, é justamente essa convicção, mais do que qualquer conteúdo específico, que dá forma ao método filosófico que caracteriza a chamada "filosofia analítica". Daí a consequência lógica de identificar Wittgenstein como um dos seus representantes, por excelência. Entretanto, o presente trabalho se ocupará em mostrar que existem outras convicções no interior do pensamento de Wittgenstein - em todos os seus "períodos" - que poderiam ser igualmente caracterizados como "continentais". Temos em mente, principalmente, um uso da noção de consciência, como também a simetria entre mundo interno e mundo externo - algo característico do idealismo, por exemplo. Poderíamos dizer que Wittgenstein é uma espécie de idealista sem sujeito. Isso porque, argumentaremos que, diferentemente de idealistas "clássicos" que são rápidos em identificar um "eu" correspondente a esse mundo interno, Wittgenstein argumenta sobre uma consciência que não tem dono, isto é, uma consciência no singular e não temporalizável. Vale reafirmar que, a forma através da qual ele chega a essa convicção "continental" é via um método distintivamente analítico, a saber, por um tratamento do uso expressivo da linguagem.

Frente ao exposto, o presente trabalho, portanto, se ocupará em mostrar como uma leitura de Wittgenstein, especificamente auxiliada pelos seus materiais do período intermediário, podem (1) nos dar uma visão mais "continuísta" do pensamento do filósofo, (2) ajudar a entender o lugar da "consciência" em sua filosofia mais madura e (3) diminuir as distâncias entre a filosofia analítica e a continental - principalmente no que

DULCI, Pedro. Contribuições e limites da abordagem analítica na filosofia da psicologia de Ludwig Wittgenstein. Griot : Revista de Filosofia, Amargosa/Bahia, v.17, n.1, p.240-255, junho/2018. 
diz respeito às questões de filosofia da psicologia. Sabemos que está totalmente fora de nosso alcance uma leitura detalhada de todo o período intermediário da produção de Wittgenstein. Sendo assim empreenderemos essa hipótese mencionada acima enfocando um elemento específico no interior de vários temas que poderiam ser trabalhados mais profundamente, a saber: o método gramatical aplicado à descrição de vivências e percepções.

\section{Psicometria, cartesianismo e psicanálise: interlocutores e abordagem de Wittgenstein}

Antes de tratarmos propriamente as contribuições de Wittgenstein ao tema anunciado, seria interessante destacarmos alguns procedimentos incontornáveis de todo trabalho filosófico. O primeiro e mais fundamental deles é tentar estabelecer qual é o problema que Wittgenstein estava abordando. Conforme o professor Mario Ariel Gonzáles Porta: “a compreensão do problema deve constituir o núcleo essencial, o eixo, tanto do ensino quanto da aprendizagem da filosofia. Não é possível 'entender' filosofia se não se entende o "problema' abordado por um filósofo" (2002, p. 15). No caso de Wittgenstein não é diferente. Na verdade, talvez seja um pouco pior, uma vez que o filósofo austríaco não se preocupa tanto em deixar explicito a quem estava se dirigindo. Consequentemente, se não temos claro diante de nós os interlocutores de Wittgenstein, fica difícil avaliar as dimensões de suas teses e argumentos. Nesse sentido, precisamos arrancar do próprio Wittgenstein suas motivações e teses.

O pano de fundo no qual se inserem as considerações do austríaco a respeito do tema em questão, é justamente o final do século XIX, em que a Psicologia, enquanto uma ciência jovem, desfrutava de um crescente prestigio no meio das teorias de conhecimento, afirmando-se cada vez mais como uma explicação empírica dos fenômenos subjetivos - e, por conseguinte, afastando-se cada vez mais da filosofia. Foi nesse período que as experiências em psicometria começaram a tornarem-se populares, explicando fenômenos psicológicos com linguagem matemática e estatuto científico. Uma vez que tais procedimentos tendiam a subestimar a importância das experiências subjetivas, não demorou muito para que ela se tornasse um dos fatores de separação entre psicólogos experimentais e psicoterapeutas.

Justamente nesse contexto de busca de estatuto científico ao conhecimento psicológico, é que se insere o projeto de um interlocutor privilegiado que, provavelmente, era quem Wittgenstein tinha em mente o tempo todo em que estava escrevendo a maioria de suas considerações sobre consciência, percepção e uso expressivo da linguagem. A saber, o filósofo Edmund Husserl. Através da ideia de uma fenomenologia, Husserl buscava recolocar a filosofia no centro das discussões científicas sobre a subjetividade. ${ }^{2}$ Para tanto, Husserl rejeita o estatuto empírico que a psicologia buscava, enquanto proposta de fundamentação da teoria do conhecimento, e lança outras bases para afirmar como o sujeito alcança certeza e evidência sobre si mesmo, para só entanto, poder tratar da realidade que lhe é exterior. O ponto de partida do método fenomenológico é o estudo

\footnotetext{
2 Já no manuscrito do Prefácio de 1913 às Investigações Lógicas, Husserl argumentou sobre a diferença de estatuto entre a psicologia, as ciências empíricas que se ocupam com o conhecimento dos fatos, e o que ele chamou de ciências puras - como a teoria do conhecimento e a lógica. Para ele, era impossível construir um conhecimento apodítico, isto é, universal e necessário, sem ocupar-se com as leis lógicas de significação geral. Tais leis são o sustentáculo de toda a unidade do conhecimento científico e não podem, de maneira alguma, serem fundadas na psicologia - por ser uma ciência empírica e, portanto, sem as condições da operar com precisão das regras lógicas (cf. 1975, p. 16-18, § 110-12).
}

DULCI, Pedro. Contribuições e limites da abordagem analítica na filosofia da psicologia de Ludwig Wittgenstein. Griot : Revista de Filosofia, Amargosa/Bahia, v.17, n.1, p.240-255, junho/2018. 
da subjetividade em si mesma, enquanto a região onde ocorrem os fenômenos da consciência - ultrapassando a visão de descrevê-la como um efeito das estruturas cerebrais, por exemplo. Somente a partir dessa modificação de abordagem será possível ultrapassar o nível empírico e alcançar as condições a priori de possibilidade de todo conhecimento, isto é, a consciência transcendental. Nesse processo de ultrapassar o empírico e chegar à consciência transcendental, existe uma operação característica da fenomenologia husserliana: a epoquē ou redução fenomenológica. Trata-se de colocar a existência de todo o mundo exterior "entre parêntesis" enquanto a investigação fenomenológica ocupa-se apenas com as operações que ocorrem na consciência. Em síntese, não se nega o mundo, mas o coloca entre parêntesis, deixando claro, assim, que a atitude de relacionar o mundo exterior com o interior não contribui para alcançarmos a fundamentação filosófica do conhecimento e das operações apodíticas da consciência.

Tais movimentos principais da filosofia husserliana são importantes para nos mostrar como se deu, no contexto de Wittgenstein, o reaparecimento do padrão internalista da filosofia de René Descartes. O professor António Marques nos é bastante útil quando argumenta que, dentre as principais motivações de Wittgenstein, estava sua tentativa de propor uma concepção não-reducionista de consciência, ou seja, manter-se distante das versões funcionalistas da consciência ou de metodologias no quadro geral do behaviorismo (cf. MARQUES, 2012, p. 14). Entretanto, Marques não se limita a dizer o que não são os alvos de Wittgenstein. Ele também nos dá um nome específico ao que o filósofo quer contrapor, a saber, "a representação cartesiana do interior" (2012, p. 14). Grosso modo, podemos dizer que a imagem cartesiana de consciência é caracterizada por (1) um privilégio epistemológico da primeira pessoa, isto é, a primeira pessoa tem acesso privilegiado aos fenômenos que ocorrem em sua consciência; e, consequentemente, (2) um privilégio dessa primeira pessoa em exprimir o que ocorre em sua consciência aos terceiros que a ouvem.

Tal postura filosófica, característica de Descartes e Husserl, reivindica a fundamentação do conhecimento rigorosamente científico a partir do relato do mundo primário por uma primeira pessoa privilegiada. Ou ainda, uma fundamentação das ciências de descrição (empíricas) a partir do mundo interno - e mais, um mundo interno que colocou o externo "em dúvida" ou "entre parêntesis". Para Wittgenstein, esse tipo de descrição é simplesmente absurda. Deixaremos claro no próximo tópico que as fronteiras de uma gramática física para uma de um testemunho subjetivo funcionam como uma gangorra: quando você levanta e exige mais de uma, mexe com a outra. Ou seja, não é possível suspender uma para concentrar-se na outra - como quer a epochēe. Elas estão relacionadas e são dependentes uma da outra, pois acontecem no ambiente da interlocução.

Por fim, existe um terceiro elemento que completa o quadro de questões e interlocutores que Wittgenstein estava lidando. Através do registro de algumas conversas que Wittgenstein teve com o ex-aluno Rush Rhees, entre 1942 e 1946, somos informados que: "durante o resto da sua vida Freud era um dos poucos autores que ele julgava que valia a pena ler" (2009, p. 79). Rhees nos conta que Wittgenstein, "quando esteve em Cambridge antes de 1914 tinha julgado que a psicologia era uma perda de tempo" (2009, p. 79). No entanto essa percepção mudou, e o próprio Wittgenstein assume que: "alguns anos mais tarde aconteceu que li qualquer coisa de Freud e fiquei muito surpreendido. Ali estava alguém que tinha qualquer coisa para dizer" (2009, p. 79). Essa modificação na perspectiva de Wittgenstein a respeito das investigações psicológicas, através da leitura

DULCI, Pedro. Contribuições e limites da abordagem analítica na filosofia da psicologia de Ludwig Wittgenstein. Griot : Revista de Filosofia, Amargosa/Bahia, v.17, n.1, p.240-255, junho/2018. 
de Freud, é muito importante para determinar melhor a forma que o filósofo encarava essa área do saber. Ainda que Freud tenha se tornando uma referência constante, e até mesmo amigo da família, Wittgenstein sempre mostrou crítico à determinadas instâncias do pensamento de Freud, por exemplificarem perfeitamente os principais problemas que o saber psicológico apresentava. Segundo outras notas de Rush Rhees:

\begin{abstract}
A teoria dos sonhos de Freud. Quer dizer que tudo o que acontece num sonho será relacionado com desejos que a análise pode esclarecer. Mas o processo destas associações livres é muito estranho, porque Freud nunca mostra como sabemos onde parar - onde está a solução certa. Diz por vezes que a solução certa ou a análise correta é a que satisfaz o paciente. Outras vezes diz que o médico sabe qual é a solução correta ou a boa análise do sonho, enquanto o doente não o sabe: o médico pode dizer que o doente está enganado. [...] Isso é especulação. É o tipo de explicação que estamos prontos a aceitar. Não é apresentada como resultado de um exame pormenorizado de variedades de alucinação. [...] Não estabelece essa opinião através de referência a um tipo de evidência - porque não poderia fazer. Mas trata-se de uma ideia que tem uma pronunciada atração. Tem a atração que as explicações mitológicas têm, as explicações que dizem que tudo isto é uma repetição de uma coisa que aconteceu anteriormente. E quando as pessoas aceitam ou adoram isso, certas coisas parecem então ser mais fáceis e claras para elas. $O$ mesmo se passa também com a noção de inconsciente. Freud alega ter encontrado provas em memórias reveladas pela análise. Mas não é claro até que ponto tais memórias se não devem ao analista. Em qualquer caso, será que estas mostram que a angústia é necessariamente uma repetição da angústia original? (2009, p. 81-82).
\end{abstract}

Nessas palavras, fica evidente que, para Wittgenstein, os resultados de Freud conclamavam para si um status científico que eles não tinham. Mais do que isso, para o filósofo austríaco, o que Freud fazia era pura especulação - algo bem anterior até mesmo da formulação de uma hipótese científica. Tudo isso fazia com que Wittgenstein enxergasse a crescente influência da psicanálise na Europa e na América como algo muito nocivo. Mesmo que Freud tivesse muito a contribuir para o cenário de excessiva ênfase nas certezas científicas que poderia ser alcançadas pela consciência fenomenológica, era necessário ser um leitor crítico das análises do inconsciente.

Frente a esse conjunto de interlocutores e questões que aludimos aqui, Wittgenstein coloca a seguinte pergunta: "podemos dizer que desnudamos a natureza essencial da consciência? 'Formação de conceitos'. Não poderia tudo isto ter sido tratado de forma diferente?" (2009, p. 85). Nessa questão o filósofo austríaco mostra que, a despeito das discussões internas à disciplina psicológica, a metodologia que ele empregaria para lidar com essas questões é genuinamente filosófica: a investigação dos princípios fundamentais de um campo de saber específico. Da mesma forma que a Matemática exigiu do filósofo austríaco uma problematização dos seus fundamentos, a Psicologia também não estava livre de um questionamento filosófico fundante. No fragmentado conjunto de seus últimos escritos sobre psicologia encontra uma passagem que também está presente nas Investigações Filosóficas, qual seja, "é possível conduzir uma investigação para a Matemática, completamente análoga à nossa investigação da Psicologia. Será tão pouco uma investigação matemática como a outra foi uma investigação psicológica. Nela não haverá cálculos, não é por exemplo, Logística. Podia merecer o nome de uma investigação dos "fundamentos da Matemática" (2001, II, xvi, p. $611)$. 
Mais especificamente, o procedimento de Wittgenstein será o de explorar as situações de assimetria entre a primeira e a terceira pessoa nos seus usos de verbos psicológicos e construções proposicionais que não fazem sentido. Ou seja, para o filósofo austríaco, as estruturas linguísticas são um acesso privilegiado para lidarmos com as questões subjetivas com um rigor que a disciplina acadêmica da Psicologia precisa ter ou seja, sem recairmos em especulações pseudocientíficas, ou mesmo em explicações psicológicas que utilizam-se de uma gramática de outra ciência. Um exemplo negativo desse princípio que Wittgenstein fornece é o do próprio Descartes. Nas Meditações Metafísicas, existe o problema do uso inadequado dos pronomes para descrever essa assimetria entre a primeira pessoa e os terceiros. Quando Descartes enunciou seu emblemático "eu penso, logo eu existo" ele desencadeou uma série de perguntas que comprometeriam o seu próprio projeto de fundamentação última do conhecimento a partir do "eu que pensa". Isso porque, nada mais natural de se perguntar: "quem é esse "eu' que pensa? Descartes?", se a resposta for sim, "ele fundamentou a existência de quem? Dele? Qual a importância filosófica disso? Descartes morreu, então ele não existe mais? Era isso que ele tinha em mente?". Em outras palavras, Wittgenstein expõe os limites da capacidade de Descarte de abordar questões complexas com linguagem cotidiana, fazendo com que seu projeto de fundamentação última do conhecimento pela subjetividade ficasse comprometido. ${ }^{3}$

De todo modo, podemos terminar esse primeiro ponto deixando claro que a metodologia filosófica de Wittgenstein será a análise da função expressiva da linguagem, que revelará as assimetrias entre as perspectivas da primeira e da terceira pessoa. Ou ainda, nas suas palavras: "uma das fontes principais de incompreensão reside no facto de não termos uma visão panorâmica do uso de nossas palavras. A nossa gramática não se deixa ver panoramicamente", e será justamente essa representação panorâmica que: "designa a nossa forma de representação, a maneira como vemos as coisas. (É isto uma "maneira de ver o mundo")?" (2001, I, §122, p.261). A partir dessas condições privilegiadas que as assimetrias entre primeira e terceira pessoa nos fornecem, conseguiremos chegar a uma imagem mais rigorosa sobre a consciência. Isso significa dizer que, através das argumentações de Wittgenstein, temos condições de ultrapassas as famigeradas descrições da consciência como falsa entidade (típica do behaviorismo), como também a igualmente problemática descrição da consciência à semelhança de "caixinhas" que cada pessoa possui, referindo-se a seu respectivo dono e situando-o em um determinado ponto da história. Ficará evidente que para Wittgenstein, a partir de sua metodologia de trabalho filosófico, que não basta a observação de um comportamento

\footnotetext{
${ }^{3}$ Grosso modo, podemos dizer que Descartes procurou resolver questões filosóficas técnicas e sutis com linguagem cotidiana. Quanto a isso, Wittgenstein diz o seguinte: "um ser humano pode encorajar-se a si mesmo, dar a si ordens, obedecer, consolar e punir a si mesmo; ele pode questionar-se e responder a si. Nós podemos imaginar seres humanos que falassem apenas em monólogos [...]. Mas nós poderíamos imaginar também uma linguagem em que uma pessoa possa escrever ou dar expressões vocais para si mesmos - seus sentimentos, humores e o descanso - para seu uso privado? Bem, não podemos fazer isso em nossa linguagem ordinária? - Eu acho que não. As palavras individuais dessa linguagem devem se referir apenas ao que sabe a pessoa que fala; às suas sensações privadas imediatas. Então, outra pessoa não podem entender essa linguagem" (2001, §243, p.335-336). Se pensarmos como essas questões e procedimentos típicos do cartesianismo reaparecem em outros filósofos da consciência, perceberemos a gravidade do problema que Wittgenstein está enfrentando. Em Hegel, por exemplo, existe uma oscilação constante na sua argumentação entre um "eu" particular e um "eu" universal - que para Wittgenstein seria totalmente absurdo e comprometeria logo de saída a proposta do filósofo alemão.
}

DULCI, Pedro. Contribuições e limites da abordagem analítica na filosofia da psicologia de Ludwig Wittgenstein. Griot : Revista de Filosofia, Amargosa/Bahia, v.17, n.1, p.240-255, junho/2018. 
externo para a atribuição do que ocorre internamente. Ao invés de tudo isso, será através do que António Marques descreve como:

A quebra do vinculo infalível entre a expressão e o que é expresso, a consequência obtenção de uma lógica própria (que nos pode permanecer desconhecida) para o interior pressupõem o aprofundamento do estudo das relações entre as formas expressivas e o material psicológico das vivências, sensações, ou experiências interna em geral. No ser humano aquilo a que chamamos "formas expressivas" vai adquirir o aspecto fundamental de formas linguísticas, o que nos introduz num universo radicalmente diferente daquele a que até agora aludimos e que seria povoado por criaturas inteligentes, como o meu cão, mas não dotadas de comportamento linguístico. [...] Ora, num ser dotado de linguagem e em particular com capacidade de exteriorizar linguisticamente (não apenas naturalmente, através de grito de dor, ou uivo, por exemplo), o interior gera-se não apenas com base na inexpressão, mas, como se verá melhor, na assimetria entre as primeiras e terceiras pessoas $(2012$, p. 18 19).

\section{Expressão, consciência e descrição em Wittgenstein}

Tendo em mente os interlocutores e os problemas que Wittgenstein está lidando, cabe agora pensar como ele os enfrenta. Isso significa arrancar do próprio Wittgenstein suas teses - arrancar porque ele não parece preocupado em deixá-las claras, de maneira didática em seus textos e anotações. Além disso, em nosso trabalho existe uma hipótese de que o período intermediário ajuda a iluminar e dar os sinais de continuidade por todo o Wittgenstein. Portanto, precisamos observar minimamente como essas teses foram aparecendo em todo percurso de Wittgenstein.

Ao colocarmos o comportamento de um indivíduo, bem como a interpretação que uma terceira pessoa faz dele, como elementos decisivos na metodologia filosófica de Wittgenstein para lidar com a subjetividade, muitos leitores são rápidos em classificar suas conclusões como behavioristas. Entretanto, algumas considerações precisam ser feitas aqui antes de restringirmos suas contribuições à disciplina psicológica. A primeira é que o comportamento para o austríaco é entendido como a unidade do ser humano em suas múltiplas expressões e exteriorizações - algo também chamado de "vivência" por alguns comentadores (cf. MARQUES, 2014, p. 22-23). Somente essa compreensão holística do ser humano é que o permite, através de uma descrição das exteriorizações, explorar o universo subjetivo do indivíduo. Ou seja, ao contrário do behaviorismo que descreve a consciência como uma falsa entidade totalmente reduzível ao comportamento, Wittgenstein reconhece o sentido de falar sobre o interior consciente de um indivíduo, mas prefere a gramática descritiva à explicação expressiva. Tal opção por descrever o exterior como meio privilegiado para acessar o interior é totalmente diferente de reduzir o segundo ao primeiro. Ou seja, ao invés de se opor a uma noção de consciência como faz o behaviorismo radical, Wittgenstein apenas nega o acesso direto a essa interioridade, optando sempre pela mediação da descrição de uma terceira pessoa ao que lhe aparece na exterioridade. Em síntese, “um "processo interior” necessita de critérios exteriores” (2001, $\S 580$, p. 461).

Esse fato nos ajuda a entender e confirmar a leitura "continuísta" que fazemos dos diferentes períodos da obra de Wittgenstein. A tradicional via introspectiva para lidar com as questões da subjetividade humana não é escolhida pelo filósofo em razão de um princípio característico da sua filosofia desde o período do Tractatus. A saber, a convicção

DULCI, Pedro. Contribuições e limites da abordagem analítica na filosofia da psicologia de Ludwig Wittgenstein. Griot : Revista de Filosofia, Amargosa/Bahia, v.17, n.1, p.240-255, junho/2018. 
de que a gramática padrão da interlocução (o ambiente mínimo para a filosofia da linguagem) é o modo descritivo. Isso significa que, os testemunhos subjetivos, com sua gramática expressiva, para operarem de maneira significativa no ambiente interlocutório, precisam assumir uma atenção especial com a sua especificidade e os seus limites de significância. Isso ajuda a entender a diferença aparentemente tão radical entre o Tractatus e as Investigações. Realmente o primeiro pode ser encarado como uma obra fisicalista, no sentido em que nele Wittgenstein está ocupado com a gramática que descreve a empiria - por isso no Tractatus, Wittgenstein não fala sobre tempo. A dimensão fenomênica (como o lugar das ocorrências subjetivas) começa a surgir no pensamento de Wittgenstein na medida em que ele introduz as suas preocupações com a temporalidade de algumas construções linguísticas. Entretanto, isso só acontecerá no chamado "período intermediário". Ou seja, entre o Tractatus e as Investigações não existe um rompimento que marca dois períodos distintos no pensamento de um autor. Antes, o que está entre eles é uma longa trajetória de desenvolvimento das hipóteses que não estavam nos primeiros anos de trabalho filosófico, mas que também não poderiam ser pensadas sem aqueles primeiros anos.

Por tudo isso, as contribuições que Wittgenstein nos fornece para pensarmos as categorias de expressão, consciência e descrição, e sua proficuidade para o saber psicológico e até mesmo à clínica psiquiátrica, precisam encontrar ressonância por todos os períodos de sua obra. Para elegermos apenas um tema específico, que nos ajuda a costurar esse raciocínio contínuo na obra de Wittgenstein, podemos utilizar algumas de suas considerações sobre as proposições a respeito das percepções em nosso campo visual. 4 Ficará evidente que não foram os tornadores de verdade da percepção que foram alterados de acordo com as "fases" do pensamento de Wittgenstein - como se no período do Tractatus fosse um, nas Observações Filosóficas outros e nas Investigações outros. Na verdade, temos continuidade e refinamento das hipóteses de Wittgenstein atribuindo papeis específicos às gramáticas distintas - de descrições físicas e de expressões subjetivas. Será justamente essa atribuição de papeis diferentes das gramáticas que fornecerá normatividade ao trabalho de clínica psicológica: "o físico ver, ouvir, refletir sobre esses fenômenos, informar-nos acerca deles, enquanto que o psicólogo observa as exteriorizações (o comportamento) do sujeito" (2001, §571, p. 458).

Podemos começar a demonstrar essa continuidade de raciocínio em todo o Wittgenstein, por exemplo, com as seguintes considerações em seus Notebooks (1914-1916) preparatórios para o Tractatus:

Vamos supor que cada objeto espacial é composto por um número infinito de pontos, então, é claro que eu não posso mencionar todos esses pelo nome quando falo desse objeto. Aqui, então, seria um caso em que eu não posso chegar à análise completa de tudo, no velho sentido, em tudo; e, talvez, apenas este é o caso usual. Mas algo é certamente claro: as proposições que são as únicas que a humanidade usa terão um sentido apenas quando elas são e não esperam uma análise futura a fim de adquirir um sentido. [...] Não é contrário ao nosso sentimento de que nós não consigamos analisar PROPOSIÇÕES a ponto de mencionarmos os elementos por nome; não, nós sentimos que o MUNDO deve consistir de elementos. $\mathrm{E}$ isto parece ser idêntico à proposição de que o mundo

\footnotetext{
${ }^{4}$ Essa ligação não é artificial, antes, encontra respaldo no próprio Wittgenstein, de onde podemos ler o seguinte: "ambos, a descrição e a exclamação, são a expressão da percepção e da experiência visual. Mas a exclamação o é num sentido diferente da descrição. Ela nos escapa - ela se comporta com relação à vivência de modo semelhante ao grito com relação à dor" (2001, II, XI, 557).
}

DULCI, Pedro. Contribuições e limites da abordagem analítica na filosofia da psicologia de Ludwig Wittgenstein. Griot : Revista de Filosofia, Amargosa/Bahia, v.17, n.1, p.240-255, junho/2018. 
deve ser o que é, ele deve ser definido. Ou, em outras palavras, o que vacila são nossas determinações, não o mundo. Parece que negar-se isto é equivalente a dizer que nosso mundo pudesse como que ser indefinido em algum sentido, como aquele em que o nosso conhecimento é incerto e indefinido. $O$ mundo tem uma estrutura fixada. É a representação por meio de nomes não analisável apenas um sistema? Tudo o que eu quero do meu conteúdo é apenas que este esteja completamente analisado. Tudo o que seu sentido tem em comum com outro sentido devem estar contidos separadamente na proposição. Se generalizações ocorrem, então as formas dos casos particulares devem estar manifestas - e está claro que esta exigência é justificada, de outra formas as proposições não poderiam ser figuras de nada (1984, p. 62-63).

Com essas palavras, Wittgenstein deixa claro que o que torna uma proposição verdadeira, falsa ou sem sentido, é um fato no mundo. Além disso, esse mundo, por conseguinte, não pode ser indeterminado, uma vez que ele tem uma estrutura determinada. Ou seja, aqui poderíamos chamar de "compatibilização" (entre mundo e descrição) o fazedor de verdade inicial de Wittgenstein. Nesse caso, as proposições não podem ser uma figuração "do nada", antes, só alcançam sentido quando a descrição é compatível com os fatos do mundo. Qualquer proposição que não se adéque a essas exigências, simplesmente, não faz sentido. Evidentemente, isso fez com que o raciocínio inicial de Wittgenstein um tanto reducionista, uma vez que essa forma de pensar as representações deixaria sem qualquer espaço as proposições de tipo indeterminado. Com o passar do tempo, foi ficando claro para o filósofo austríaco que uma impressão visual não pode ser compreendida da mesma forma que uma descrição de uma figura do mundo. As impressões visuais não conseguem acompanhar as exigências de singularização e exatidão de uma descrição. Todas as vezes que alguém abre uma gaveta rapidamente, por exemplo, mesmo que esteja procurando um objeto específico, muitas vezes essa pessoa simplesmente não encontra nada, porque tem uma impressão geral do que há dentro da gaveta. Tais problemas relacionados à percepção levaram Wittgenstein a continuar refinando seus argumentos em busca de uma figura que representasse essa generalidade. Nessa altura, o período intermediário começa a ser muito útil para nos ajudar a compreender continuidade do raciocínio do filósofo. Podemos ler no The Big Typescript (1933-1937) o seguinte:

\footnotetext{
A base da expressão "peneira" é esta: se eu olho para, digamos, uma paisagem através de um vido que transmita apenas a distinção entre brilho e escuridão e não as distinções entre as coisas, tal vidro poderia ser chamado de uma peneira. Imaginemos agora o quadrado visto através de um vidro que deixasse passar apenas a diferença entre "circulo no quadrado e não no quadrado", mas não as diferenças entre posições e tamanho do círculo. Nesse caso, aqui também poderíamos falar em uma peneira $(2005$, p. $242, \S 70)$.
}

Nesse trecho, Wittgenstein busca estabelecer uma espécie de figura que também fosse uma representação geral - algo impossível de se alcançar e que posteriormente ele irá abandonar: "uma imagem [Vorstellung] não é uma figura, mas uma figura pode corresponder a ela" (1986, §301, p. 101). Isso porque, uma figura diz respeito a representações no espaço e no tempo, isto é, da experiência empírica, enquanto o que ocorre na consciência são imagens. Essas últimas, não estão podem estar sujeitas aos mesmos critérios de identificação com os objetos no mundo. Entretanto, no trecho supracitado do The Big Typescript é precisamente o que Wittgenstein está buscando, uma figura com propriedades de imagem. Ficará evidente logo à frente que se trata de um

DULCI, Pedro. Contribuições e limites da abordagem analítica na filosofia da psicologia de Ludwig Wittgenstein. Griot : Revista de Filosofia, Amargosa/Bahia, v.17, n.1, p.240-255, junho/2018. 
típico erro de aplicar uma gramática tipicamente físicalista àquilo que é característico das impressões internas que não estão submetidas à mesma precisão exigida das primeiras.

Nesse sentido, aqui no trecho do The Big Typescript, temos diante de nós algo que, precisamente por isso, nos chama atenção: o aparecimento de sua preocupação em ressaltar diferenciações, as distinções entre brilho e escuridão, posição, tamanho e forma. Para que as representações não fiquem ambíguas - o próprio termo representação é ambíguo - Wittgenstein precisará fazer distinções somente em sua maturidade estão totalmente prontas. Todavia, enquanto chegamos lá, o período intermediário nos ajuda, pois, já aqui no The Big Typescript vemos o austríaco dizendo que:

Tomado dessa forma, vê-se a figura [picture] como pertencentes a um sistema diferente do que quando se a vê como representando uma posição particular do círculo entre as linhas retas. Ou, mais corretamente: tomado dessa forma, isto é uma parte de um cálculo diferente. As regras que se aplicam a uma variável são simplesmente diferentes das que se aplicam ao seu valor particular. [...] Isto é, quando estamos falando sobre as posições individuais (que temos visto), parece que estamos falando de algo totalmente diferente do que é falado na proposição geral $(2005, \S 70$, p. 241).

Com essas palavras, Wittgenstein introduz a diferenciação de sistemas, ou mais corretamente, uma diferenciação de cálculos entre impressões gerais (como, por exemplo, uma "multidão" ou um "rabisco") e as representações particulares e determinadas ("cada uma das pessoas", ou a "forma específica feita pelo lápis"). Mas para isso, precisamos fazer diferenciações nos cálculos quanto ao tipo de precisão que requeremos de cada uma delas. Algo que permanece até às Investigações Filosóficas quando Wittgenstein levanta outro exemplo: "quando eu digo a alguém: "pare mais ou menos aqui' - essa elucidação pode não funcionar perfeitamente? E qualquer outra não pode falhar também? Mas não é uma explicação inexata? - Sim; porque não devemos chamá-la de 'inexata'? Apenas vamos entendermos o que "inexato' significa" (1986, § 88, p. 41).

Tais exemplos, como "aqui em volta", "a multidão", ou "um monte de rabiscos" são várias imagens gerais que precisam ser diferenciadas das figuras singulares que conseguimos descrever com precisão. Essa diferenciação, que começa de maneira vacilante em alguns trechos do The Big Typescript, encontrará o seu cume naquilo que podemos chamar de método gramatical - exatamente aquilo que acreditamos ser uma contribuição de Wittgenstein para a disciplina psicológica. Em outras palavras, trata-se do tipo de argumentação que facilita as dificuldades ontológicas que teríamos de distinguir entre "o que existe" e "o que não existe" em determinadas percepções, mas que, semanticamente, são bastante adequadas quando apresentadas como "faz sentido dizer..." ou "não faz sentido dizer..." no interior de uma gramática específica. Ou ainda, a gramática da fala sobre impressões visuais é diferente das proposições empíricas.

Quanto a isso, o período intermediário nos auxilia novamente. No material reunido e publicado sob o título The Voices of Wittgenstein, temos uma série de textos que datam do período de 1928-1939. Em uma seção a respeito da Linguagem Fenomenal, Wittgenstein tinha em seu horizonte a questão sobre a possibilidade de "imaginar uma linguagem tão sutil que reproduz os detalhes mais finos? Uma que não é, como a nossa linguagem cotidiana, uma esquematização dos fatos, mas sim nos dá a realidade na sua totalidade?" (2003, p. 313). Com essa busca, ele sabia que não estava se referindo a linguagem dos fatos físicos, "podem ser captados com bastante precisão pela medição e contagem. Os fatos que temos em mente são os fenômenos, aquilo que ocorre

DULCI, Pedro. Contribuições e limites da abordagem analítica na filosofia da psicologia de Ludwig Wittgenstein. Griot : Revista de Filosofia, Amargosa/Bahia, v.17, n.1, p.240-255, junho/2018. 
imediatamente. Assim, este realmente se resume à questão: pode a fugaz experiência ser capturado em sinais?" (2003, p. 313). Nessa questão, vemos claramente o avançar das preocupações de Wittgenstein em refinar e diferenciar gramáticas específicas para ocorrências diferentes. Ainda que, nesse momento ele não chegue a uma formulação final e "oficial" do método gramatical, já podemos ler nesse texto o que estava no cerne de suas preocupações:

\begin{abstract}
Agora estamos começando a obter uma precisão sobre todo o equívoco que está subjacente à busca de uma linguagem tão ideal. Aquele que quer usar sinais para apreender a experiência é enganado pela ambiguidade das palavras "grosseiramente", "aproximadamente", etc. Ele não percebe que a palavra "aproximadamente" desempenha um papel inteiramente diferente na descrição de uma vivência do que aquela (digamos) da medição de uma distância. Nesse último caso (aqui, novamente em um sentido específico) para cada "aproximadamente" corresponde um "exatamente". Também no primeiro caso ele espera encontrar, para cada "aproximadamente" um "exatamente" - e acaba perseguindo uma miragem que o ilude constantemente. Essa ideia falsa pode no final das contas ser atribuída à confusão da imagem da tela encarada com uma imagem física. È muito diferente dizer "a descrição deve aproximar-se da de uma imagem pintada" do que dizer "a descrição deve aproximar-se de uma imagem visual". No primeiro caso, eu poderia copiar a imagem, e na verdade poderia fazer bem, e aqui faz sentido dizer que a cópia reproduz exatamente o original. Mas aplicado à imagem visual, esta expressão perde o seu sentido (2003, p. 317).
\end{abstract}

Temos aqui um trecho muito importante para a nossa hipótese. Nele Wittgenstein fala de desempenho de funções diferentes que, se forem transpostas para contextos que não são os seus, geram ambiguidades comprometedoras em nosso processo interlocutório. Além disso, também percebemos já nesse período a relação de interdependência entre as diferentes gramáticas, não permitindo que ninguém consiga produzir um discurso sobre a subjetividade humana desvinculado da realidade externa do mundo - como pretendeu Husserl com a suspensão fenomenológica. Ainda que a descrição de uma vivência precise operar segundo uma gramática diferente da descrição empírica, ela mantém correspondência com tal realidade externa - por isso a importância do comportamento para a subjetividade. Ou seja, conseguimos perceber, já no período intermediário, algo que ficará evidente no final de sua vida: sua oposição às concepções de consciência que são elaboradas fora do ambiente interlocutório - algo que, para ele, além de não ser possível, é a raiz de muitos problemas filosóficos bem como de abordagem psicológica.

$\mathrm{O}$ estudo do período intermediário também nos mostra que durante as palestras do ano acadêmico de 1930-31, quando Wittgenstein acabara de regressar à Cambridge, o filósofo já estava com formações mais refinadas das diferentes gramáticas e suas fronteiras em questão. ${ }^{5}$ Tendo esse instrumental teórico em mãos, Wittgenstein tem

\footnotetext{
5 Através das anotações de G. E. Moore, somos informados das definições de cada gramática: "a palavra "proposição", "como geralmente entendido", inclui tanto "o que eu chamo de proposições", como também "hipóteses", e também proposições matemáticas; que a distinção entre estes três "tipos" é uma "distinção lógica", e que, portanto, deve haver algumas regras gramaticais, no caso de cada tipo, que se aplicam a esse tipo e não para os outros dois; mas que as regras de "função de verdade" se aplicam a todas as três, e que é por isso que todas elas são chamados de "proposições" (1954, p. 10). Além de especificar e dar nome aos três tipos de definições, ele também deixa claro que elas permanecem relacionadas entre si. Para ilustrar a diferença entre as três gramáticas Moore diz que: "Ele continuou a ilustrar a diferença entre os dois primeiros tipos de dizer que "me pareceu ser um homem aqui" é do primeiro tipo [proposições], enquanto "Há um homem aqui" é uma "hipótese"; e disse que uma regra que se aplica a primeira e não a segunda é que eu não posso dizer "me pareceu parecer-me ser um homem aqui", enquanto que eu posso dizer "Não me pareceu ser um DULCI, Pedro. Contribuições e limites da abordagem analítica na filosofia da psicologia de Ludwig Wittgenstein. Griot : Revista de Filosofia, Amargosa/Bahia, v.17, n.1, p.240-255, junho/2018. 
condições de desenvolver seu raciocínio específico para as questões psicológicas: explorar as fronteiras entre os enunciados descritivos do mundo externo e os enunciados expressivos do mundo interno, mostrando os limites de cada um. Se pudéssemos imaginar uma tabela em que as gramáticas fossem colocadas com seus respectivos papéis desempenhados, poderíamos falar que a ordem decrescente de exigência em precisão constante seria: as regras matemáticas, seguidas das proposições empíricas, para só depois aparecerem os relatos subjetivos. Por isso que Wittgenstein já havia afirmado no período coberto pelo The Voices of Wittgenstein que precisamos perceber que o "aproximadamente" ou o "grosseiramente" desempenham um papel totalmente diferente de uma descrição de vivência empírica - como também de uma regra matemática. $O$ mesmo pode ser dito quanto à completude, no diz que respeito a pedir detalhes de cada enunciado em uma gramática diferente. Em ordem, sempre teremos primeiro os enunciados matemáticos necessários, as proposições empíricas e, por último, os testemunhos subjetivos da primeira pessoa. Exigir precisão matemática ou empírica das vivências interiores é transgredir os limites da gramática que é própria da subjetividade.

A partir de tudo isso, Wittgenstein tem condições de nos explicar, nas suas palestras em Cambridge, o seguinte relato de Moore:

\begin{abstract}
A este respeito, ele disse que achava que tanto o Realista quanto o Idealista estavam "falando bobagem", no sentido específico no qual a "falta de sentido é produzida pela tentativa de expressar pela linguagem o que deve ser incorporado na gramática"; e ele ilustra esse sentido através da seguinte fala: "eu não posso sentir a sua dor de dente" significando "sinto sua dor de dente", não tem sentido" e, portanto, não "expressa um fato" como "eu não posso jogar xadrez" pode fazer (1955, p. 16).
\end{abstract}

Recorrer à determinação das fronteiras entre o discurso da primeira e o da terceira pessoa, como meios de determinar os limites da fala psicológica com sentido, é uma manobra filosófica muitíssimo profícua para nossos interesses. Essa diferenciação nos fornece uma forma mais segura de lidar com as experiências psicológicas: "você pode determinar o sentido de uma proposição perguntando como ela é verificada" (1954, p. 14). Quanto às condições de verificação, Wittgenstein ainda insistiu por algum tempo no período intermediário no privilégio da primeira pessoa para os fazedores de verdade das ocorrências no seu interior. Entretanto, no final de suas investigações ele estará convencido de que só as proposições empíricas desempenham esse papel. Isso não significa a eliminação dos testemunhos subjetivos do processo interlocutório, mas a cautela de não exigir indevidamente o que é típico de outras gramáticas. Ou seja, a diferenciação do que faz sentido em cada tipo de enunciado nos ajuda a atribuir àquele rigor que a disciplina psicológica programa no século XIX sem com que seja necessário recorrermos aos dualismos metafísicos, ou reducionismos materialistas consolidados na história da filosofia da mente e da psicologia.

Com essa diferenciação entre linguagem primária e secundária, como também através da caracterização do que é próprio de cada uma delas, Wittgenstein terá condições de explorar melhor a realidade - que permanece apenas uma - através de duas gramáticas. Enquanto a gramática física nos fornece fazedores de verdade para os fatos

homem aqui" (1954, p. 10). Claramente o que ele chamou de "hipóteses" são os enunciados empíricos ordinários - que podem acontecer e, por isso, podem ser verificados na experiência imediata daquele que fala e de quem o ouve. Em segundo lugar, temos as proposições genuínas - que são, na verdade, testemunhos subjetivos da primeira pessoa. Por fim, o terceiro tipo de gramática são as proposições matemáticas, ou ainda, as regras enquanto enunciados necessários.

DULCI, Pedro. Contribuições e limites da abordagem analítica na filosofia da psicologia de Ludwig Wittgenstein. Griot : Revista de Filosofia, Amargosa/Bahia, v.17, n.1, p.240-255, junho/2018. 
no mundo, os testemunhos subjetivos ficam responsáveis por expressar as ocorrências da consciência. Estas últimas não possuem a mesma possibilidade de precisão e detalhamento que os enunciados empíricos, mas em um ambiente interlocutório podem ser testadas pela correspondência coma descrição de um comportamento. ${ }^{6}$ Exigir tal exatidão das expressões de primeira pessoa seria como querer encontrar, por exemplo, "o tempo exato" de uma impressão que ocorre na consciência. Nas suas palavras: "é um erro de compreensão fundamental sentir-me inclinado a investigar a dor de cabeça que eu sinto agora, a fim de esclarecer o problema filosófico da sensação" (1986, §314, p. 104).

Em tudo isso, fica explicito os limites da fronteira entre um testemunho interno sobre ocorrência de dor na consciência, e seu correlativo comportamental - que pode ser verificado, uma vez que está sendo exibido. Tal modificação nos auxilia a eliminar tratamentos simplistas das vivências dos indivíduos - como, por exemplo, a máxima muito popular: "uma pessoa não pode fazer uma ideia do que são, a não ser que as tenha alguma vez sentido" (1986, §315, p. 104). Wittgenstein estava consciente de que "fazer uma ideia da dor de outrem a partir do modelo da minha própria dor, então isso não é de todo uma coisa simples de fazer" (1986, §302, p. 101). Ao invés disso, ele nos resume quais são suas propostas filosóficas para o saber psicológico:

\footnotetext{
"Mas tens que concordar que existe uma diferença entre comportamento de dor com dores e comportamento de dor sem dores". - Concordar? Não há maior diferença! - "E, no entanto, chegas sempre ao resultado de que a sensação em si mesma é um nada". - Não, de todo! A sensação não é uma coisa, mas também não é um nada! O resultado foi que tanto podia servir um nada como uma coisa acerca da qual nada se pode dizer. Repudiamos apenas a gramática que se quer aqui impor a nós. O paradoxo dissolve-se apenas se cortamos radicalmente com a ideia de que a linguagem funciona sempre de uma maneira, serve sempre a mesma finalidade: transmitir pensamentos, sejam estes pensamentos acerca de casas, de dores, do bem e do mal, etc. $(1986, \S 304$, p. 102).
}

Através desse diálogo imaginário, Wittgenstein refina exatamente as possibilidades que estamos lidando em uma filosofia da psicologia. Em primeiro lugar, ele concorda que faz sentido falarmos sobre a possibilidade de um comportamento de "dor sem dor", ou seja, de dissimulação ou auto-engano. ${ }^{7} \mathrm{Em}$ segundo lugar, o filósofo mostra que é possível a acusação de que ele chega a um resultado semelhante ao do behaviorismo: de que as ocorrências subjetivas são um nada. Entretanto, ele refuta isso, e explica que: ainda que uma sensação não tenha as mesmas características de um fato empírico (que pode ser descrito com alguma precisão), ela não é uma pseudo-entidade. Parte dessa confusão, ele menciona, em terceiro lugar, é decorrente do fato de que tal

\footnotetext{
${ }^{6}$ Nas palavras de Wittgenstein: "paralelo enganador: a expressão de dor é um grito - a expressão do pensamento, uma proposição. Como se o propósito da proposição fosse convencer uma pessoa como é a outra: apenas, por assim dizer, em sua parte pensante e não em seu estômago" (1986, §317, p. 104).

7 A dissimulação e o autoengano surgem no projeto de Wittgenstein como "situações limites", isso porque, alguém poderia dizer que nessas situações o privilégio do acesso da primeira pessoa retornaria. Entretanto, para Wittgenstein, ao invés de inviabilizarem sua proposta, tais situações reafirmam-na. Mesmo que a primeira pessoa expresse seus mais profundos sentimentos de amor por seu cônjuge, por exemplo, ela pode demonstrar o tempo todo para os terceiros o odeia. Em uma situação de descompasso entre expressão e comportamento como essa, a terceira pessoa tem privilégio de veracidade sobre o discurso da primeira. É interessante observar o próprio Wittgenstein formulando esse raciocínio:"Quando eu digo 'eu estou com dor' eu estou, em todo caso, justificado perante mim mesmo" - o que isso significa? Será que isso significa: "se alguém pudesse saber o que estou chamando de 'dor', ele iria admitir que eu estou usando o palavra corretamente"? Usar uma palavra sem uma justificação não significa usá-lo sem direito [right] (1986, $\S 289$, p. 99).
}

DULCI, Pedro. Contribuições e limites da abordagem analítica na filosofia da psicologia de Ludwig Wittgenstein. Griot : Revista de Filosofia, Amargosa/Bahia, v.17, n.1, p.240-255, junho/2018. 
ambiguidade poderia surgir de uma tentativa de descrever "uma coisa" da qual não se pode falar - algo que era procurado no Tractatus. No interior dessa exploração das fronteiras entre as duas gramáticas, ficará evidente que, na medida em que cobramos mais o que é específico de uma gramática a outra precisa ser menos cobrada - ficando evidente uma vez mais o processo de gangorramento das duas gramáticas. Entretanto, o que nunca acontecerá para Wittgenstein é a busca de justificação de um enunciado através da eliminação ou suspensão do outro - como falamos a respeito de Husserl anteriormente.

Justamente por isso, foi necessário continuar refinando o tratamento das estruturas do pensamento a partir da estrutura da linguagem, ampliando o número de usos dessa linguagem. Ou seja, para não cairmos em um reducionismo comportamentalista, ou em ambiguidades metafísicas, é necessário diferenciar usos da linguagem para finalidades distintas. Em suas palavras, "o que aqui parece ser uma explicação ou uma asserção acerca de processos da consciência é, na verdade, uma troca de uma maneira de falar por outra, que nos parece mais acertada quando fazemos filosofia" (1986, §303, p. 102).

\section{Conclusões}

Do ponto de vista meramente do interior da obra de Wittgenstein, esses resultados já são interessantes. Percebemos uma continuidade em seus esforços, que vai desde uma perspectiva reduzida até o detalhamento diferencial refinado da análise da linguagem. $O$ significado na interlocução é uma aposta filosófica que fornece dimensões públicas à própria filosofia. Isso porque, conforme tentamos deixar evidente, a raiz dos conteúdos de nossas críticas às visões reducionistas da consciência ou as formulações mais adequadas sobre o que é distinto em cada gramática possível, sempre é fruto de uma triangulação com terceiros. Não se trata de construir um sistema filosófico complexo no isolamento do "eu que pensa". Ao invés disso, entregamos nas mãos daqueles que nos ouvem a responsabilidade de colocar nossas próprias afirmações em questão - inclusive, afirmações sobre nós mesmos. Como já dizia Wittgenstein: "pensar não é um processo incorpóreo que empresta vida e sentido ao ato de falar, e que pudéssemos separar do falar" $(1986, \S 339$, p. 109).

Esses esforços fornecem a Wittgenstein noções que, para alguns, são inusitadas a partir do contexto em que o austríaco está - como, por exemplo, a noção de consciência. Entretanto, acima de tudo, as consequências éticas de tais formulações a respeito da subjetividade, são muito interessantes. Diferentemente do que tem sido afirmado de modo geral a respeito da subjetividade, não somos nós mesmos os árbitros privilegiados de nossos testemunhos subjetivos. Atribuições de terceiras pessoas são tão, ou em algumas circunstâncias até mais, importantes do que enunciados de primeiras pessoas para dizer o que verdadeiramente ocorre na consciência. Com toda certeza, isso nos leva a necessidade de pensarmos uma ética da responsabilidade diante do outro que ouve e prova os enunciados primários.

Entretanto, é importante deixar claro que tal "via alternativa" de Wittgenstein não está livre de especificidades tão singulares que soaria estranho aos psicólogos e psiquiatras. Mesmo afirmando uma noção de consciência, o raciocínio de Wittgenstein não nos permite atribuir um "dono" a essa consciência. O fato é que, toda tentativa de temporalizar experiências da consciência geram discursos ambíguos, como os de Descartes - "eu penso, logo existo", quem existe? Descartes? Por quanto tempo? E

DULCI, Pedro. Contribuições e limites da abordagem analítica na filosofia da psicologia de Ludwig Wittgenstein. Griot : Revista de Filosofia, Amargosa/Bahia, v.17, n.1, p.240-255, junho/2018. 
depois que ele morrer? Ou seja, trata-se de um uso de linguagem descritiva para lidar com vivências subjetivas. Tudo isso faz com que não seja possível para nós atribuirmos a uma pessoa historicamente localizável a posse daquilo que ocorre no ambiente da consciência está fora das capacidades específicas da gramática das expressões. $O$ máximo que se pode fazer em relação à atribuição de temporalidade aos fenômenos na consciência são as recordações. Nesse sentido, de maneira pouco convencional, poderíamos dizer que Wittgenstein argumenta em prol de uma consciência sem dono.

Mesmo diante de tal conclusão pouco "ortodoxa" para os estudos psicológicos, estamos convencidos de que através da diferenciação entre as "auto-atribuições" e "atribuições de terceiros", Wittgenstein consegue lidar com as principais questões que se colocam à frente de todo aquele que investiga o estatuto do saber psicológico. A diferenciação das gramáticas, bem como a privilégio das atribuições de terceiros no saber psicológico, tem por resultado: (1) evita que ambiguidades surjam no discurso sobre a subjetividade (como produziu Descartes); (2) não permitir que um tipo característico de linguagem elimine o outro (como acontece no behaviorismo); ou que (3) seja necessário suspender um tipo de enunciado para que, só então, o outro tenha sentido (como faz a fenomenologia). Ao invés disso, Wittgenstein consegue nos fornecer uma forma de explorar tanto o mundo interior e o exterior, mantendo-os correlacionados (expressão e comportamento) e de uma forma rigorosa (sem exigir detalhamentos inadequados). Em síntese, é possível sustentarmos a incomum hipótese de uma posição filosófica tipicamente "continental" alcançada por uma metodologia rigorosamente "analítica". 


\section{Referências bibliográficas}

HUSSERL, Edmund. Introduction To The Logical Investigations. A Draft Of A Preface To The Logical Investigations (1913). Edited By Eugen Fink. Translated With Introductions By Philip J. Bossert And Curtis H. Peters. Martinus Nijhoff: 1975. The Hague

MARQUES, António. O interior: linguagem e mente em Wittgenstein. São Paulo: Loyola, 2012 .

. Vivência e Significado. In: WITTGENSTEIN, Ludwig. Últimos Escritos sobre a filosofia da psicologia. Trad. Antonio Marques, Nuno Venturinha e João Tiago Proença. Fundação Calouste Gulbenkian, Lisboa, 2014

MICHELETTI, Mário. Filosofia analítica da religião. São Paulo: Loyola, 2007.

MOORE, G. E. Wittgenstein's Lectures in 1930-33. In: Mind: a quarterly review of Psychology and Philosophy. Vol LXIII. No. 249, January, 1954

. Wittgenstein's Lectures in 1930-33. In: Mind: a quarterly review of

Psychology and Philosophy. Vol LXIII. No. 253, January, 1955

PORTA, Mario Ariel Gonzáles. A filosofia a partir de seus problemas. São Paulo: Loyola, 2002.

WITTGENSTEIN, Ludwig. Notebooks 1914-1916. Edited G. H. von Wright and G. E. M. Anscombe. Harper Torchbooks, New York and Evanston, 1984.

. Philosophical Investigations. Translated By G. E. M. Anscombe. Basil

Blackwell, 1986.

Tractatus Logico-Philosophicus. Translated by D. F. Pears and B. F. McGuinness. With an introduction by Bertrand Russell. Routledge: London and New York, 2001.

Investigações Filosóficas. Tradução e Prefácio de M. S. Lourenço. Fundação Calouste Gulbenkian, Lisboa, 2001.

The Voices of Wittgenstein: The Vienna Circle. Ludwig Wittgenstein and Friedrich Waismann. Transcribed, edited and with an introduction by Gordon Baker. Routledge: London and New York, 2003.

The Big Typescript, TS 213. Edited and translated by C. Grant Luckhardt and Maximilian A. E. Aue. Blackwell Publishing Ltd, 2005.

Aulas e conversas.Trad. Miguel Tamen. Cotovia, Lisboa, 2009.

. Últimos escritos sobre a filosofia da psicologia. Trad. Antonio Marques, Nuno

Venturinha e João Tiago Proença. Fundação Calouste Gulbenkian, Lisboa, 2014.

Autor(a) para correspondência: Pedro Dulci, Universidade Federal de Goiás, Faculdade de Filosofia, Av Esperança, SN, Campus Samambaia. Conj. Itatiaia, CEP 74690-900

Goiânia - GO, Brasil. pedrolucas.dulci@gmail.com

DULCI, Pedro. Contribuições e limites da abordagem analítica na filosofia da psicologia de Ludwig Wittgenstein. Griot : Revista de 